\title{
Failure rate analysis of Jaw Crusher: a case study
}

\author{
R S SINHA* and A K MUKHOPADHYAY \\ Department of Mining Machinery Engineering, Indian Institute of Technology (Indian School of Mines), \\ Dhanbad 826004, India \\ e-mail: ravishankarism0181@gmail.com
}

MS received 18 July 2014; revised 31 March 2016; accepted 30 October 2018; published online 2 January 2019

\begin{abstract}
Failure of crusher components has considerable influence on the productivity of a crushing plant. In order to improve performance and operational reliability, its critical components are needed to be identified to make replacement in time before any catastrophic failure happens. Though traditional maintenance practices exist in crushing plants, a methodical analysis of failure trend is imperative to improve operational reliability of this critical equipment. The present paper deals with failure analysis of rock crusher and its critical components using total time on test (TTT)-plot and other statistical tools. TTT-plot has proven to be a useful tool in reliability analysis.
\end{abstract}

Keywords. Total time on test; Jaw Crusher; time between failures; life data analysis.

\section{Introduction}

Maintenance and operational reliability are considered as important issues for un-interrupted plant equipment operation. The sudden and frequent failure of equipment components will lead to production loss. This becomes more critical for modern plant equipment in which plant owner have invested a major share of their capital investment. These machines demand correct, precision and time driven maintenance. Maintenance to be scheduled in time but becomes impossible without a methodical study on the trend of failure of the equipment and its components. Operational reliability investigation is desirable for reducing the maintenance cost of the plant equipment. The present study has examined failures of jaw crusher and its components in a major mineral processing plant. The failure data of two year duration are recorded from the plant maintenance register for analysis purpose. Maintenance and operational reliability using TTT-plotting has been already carried out for a fleet of diesel operated load haul dump (LHD) machines in a Swedish mine [1]. The same concept with additional statistical treatments has been considered here. Analytical methods such as Life Data Analysis (LDA) test and Maximum Likelihood (ML) estimation are also considered in this study. Failure data are examined through different statistical distributions. Their parameters are estimated using ML (maximum likelihood) method $[2,3]$. ML estimation is used at confidence level of $90 \%$. Confidence bounds can be expressed as two-sided or one-

*For correspondence sided. Two-sided bounds are used to indicate that the quantity of interest is contained within the bounds with a specific confidence. The graphical TTT-plot is used to examine increasing or decreasing trend of failure rates of components and the results are compared with the findings by ML method. Graphical techniques are used to test the independence and identical distribution (iid) of the data. LDA test is used for goodness of fit of the data for different distributions. The 2-Parameter Weibull distribution density function is given by the following equation.

$$
f(t)=\frac{\beta}{\eta}\left(\frac{t}{\eta}\right) \beta e^{-\left(\frac{t}{\eta}\right) \beta} \ldots, \quad \beta>0, \eta>0
$$

In Weibull plot, the parameter $\beta$ describes the Weibull slope or shape parameter, i.e., The failure rate and change of failure rate (increasing or decreasing). The $\eta$ is scale parameter which indicates the mean time between failures (MTBF). The primary advantage of Weibull distribution is the ability to provide reasonably accurate analysis with extremely small data size.

\subsection{The mineral processing plant layout}

A mineral processing plant circuit consisting of different operating units is shown in figure 1. In the circuit there is no stand by equipment. So, if one particular unit in the circuit is down, the whole operation stops, causing production loss of the plant. Maintenance of the units in time to improve operational reliability thus becomes essential. 


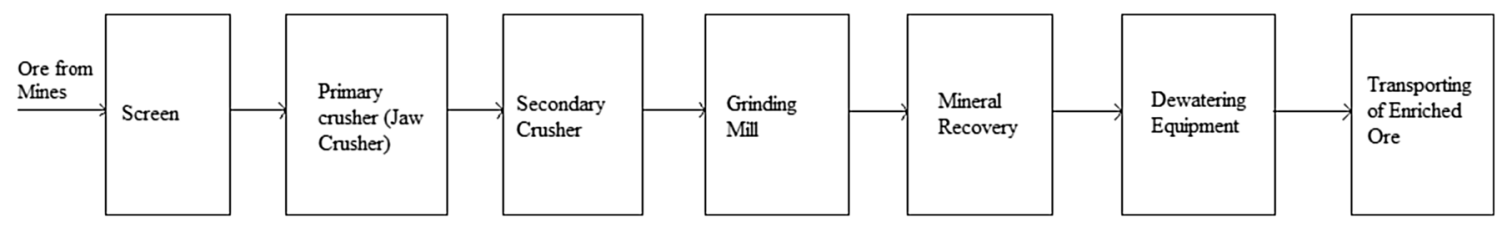

Figure 1. Block diagram of operational units.

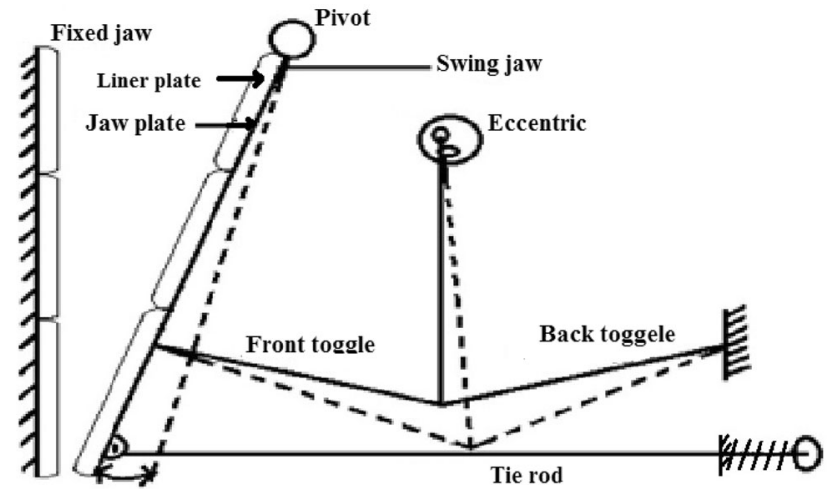

Figure 2. A double toggle jaw crusher.

\subsection{The jaw crusher}

Crushing is the first stage of size reduction of mined rocks. Primary crushers are heavy-duty machines, used to reduce the run-of-mine (ROM) ore down to a size suitable for easy handling. A line diagram of a double toggle jaw crusher and its main components is shown in figure 2. The jaws are set at an angle to each other. The moving jaw moves gradually forward towards the fixed jaw causing fragmentation of rocks trapped inside the crushing chamber and then moves backward in the next half of its working cycle. The crushed materials get discharged from the bottom of the crusher during the return stroke by gravity.
Table 1. TBFs of the crusher and their components.

\begin{tabular}{|c|c|c|}
\hline System/subsystem & $\begin{array}{l}\text { No. of } \\
\text { failures }\end{array}$ & Time between failure (hours) \\
\hline Jaw crusher & 40 & $\begin{array}{c}250,370,380,396,273,300,324, \\
135,165,180,405,410,420, \\
185,200,216,108,110,132, \\
360,360,360,60,70,431,432, \\
432,330,340,350,360,425, \\
430,430,360,365,400,225, \\
245,12\end{array}$ \\
\hline Back toggle & 11 & $\begin{array}{c}396,600,650,711,767,1800,455 \\
567,800,790,800\end{array}$ \\
\hline Liner plate & 10 & $\begin{array}{c}888,500,560,636,670,730,600 \\
610,620,492\end{array}$ \\
\hline Jaw plate & 9 & $\begin{array}{c}60,100,810,1100,1248,210,400, \\
556,708\end{array}$ \\
\hline Tie rod & 10 & $\begin{array}{c}708,950,1100,790,810,828,720 \\
750,900,1320\end{array}$ \\
\hline
\end{tabular}

\subsection{The concept and data analysis technique}

This work analyzes failure rates of crusher and its components using LDA method, ML method and TTT-plots. The ML method needs application of software for solving mathematical equations. The TTT-plotting does not need structured data set. The method assumes that TBFs are independently and identically distributed (iid). To established validity of this assumption, statistical tests are performed to examine the presence of structure or trend in the data.

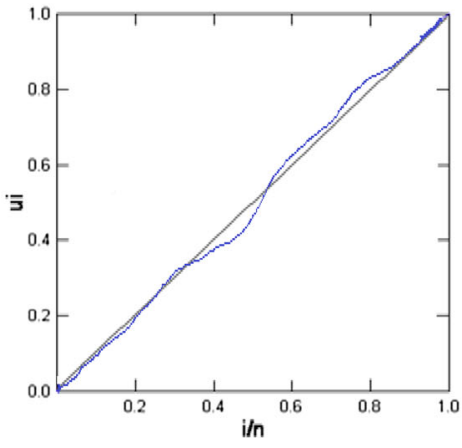

(a) TTT-plot for constant failure rate

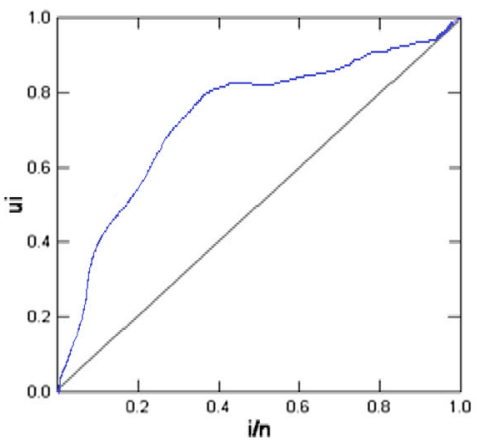

(b) TTT-plot for increasing failure rate

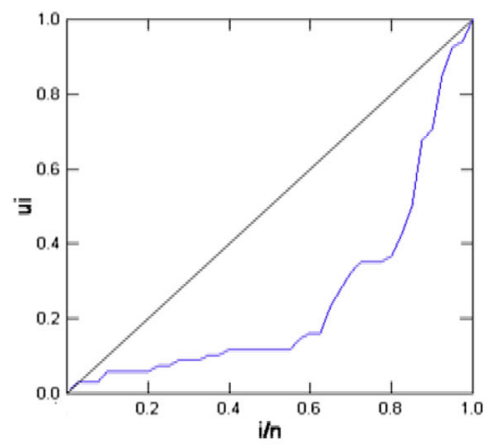

(c) TTT-plot for decreasing failure rate

Figure 3. TTT-plots at different failure rates. 

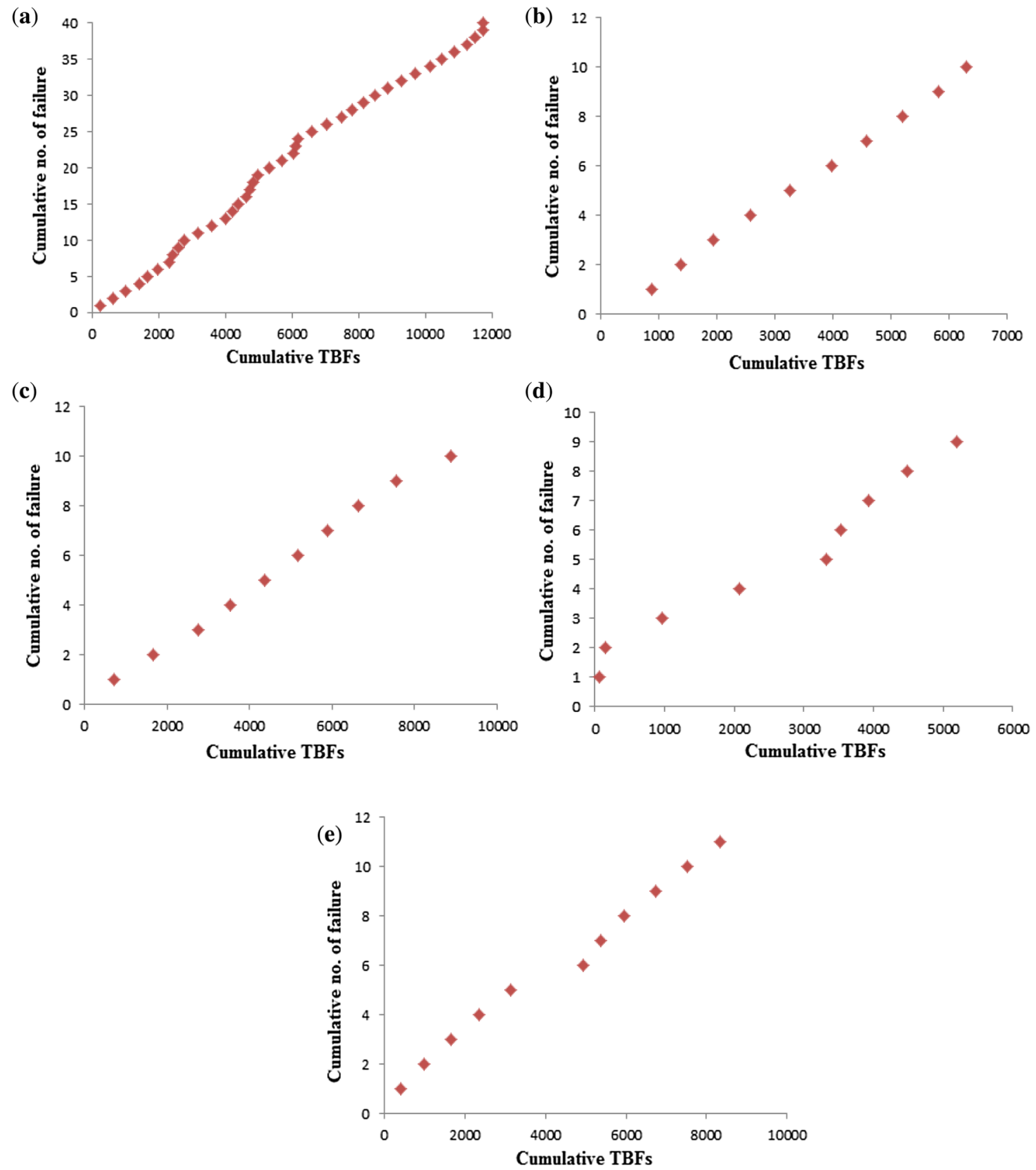

Figure 4. Plots confirming identical trend of data for (a) Jaw crusher unit, (b) Liner plate, (c) Tie rod, (d) Jaw plate and (e) Back toggle.

\subsection{Data collection and treatment of data}

The failure data of two year duration are collected from the plant maintenance record book. The components of crusher which are critical and having major impact on plant's operation have been considered for analysis. TBFs of these components are presented in table 1 . The unit of the TBF is hours. TBFs obtained due to stoppage of routine maintenance are classified as censored data. When a major breakdown occurred, the jaw crusher itself was considered as a component.

\section{Methodology}

\subsection{TTT-plot}

TTT-statistics were first used by Epsten et al [4]. In the last decade, different generalizations of this concept have been studied and applied to different areas of reliability [5]. The TTT-plot is used to analyze the trend of equipment failures. The plots help in formulating a suitable mathematical model from failure data and provide information about failure rate. Also, inconsistent 

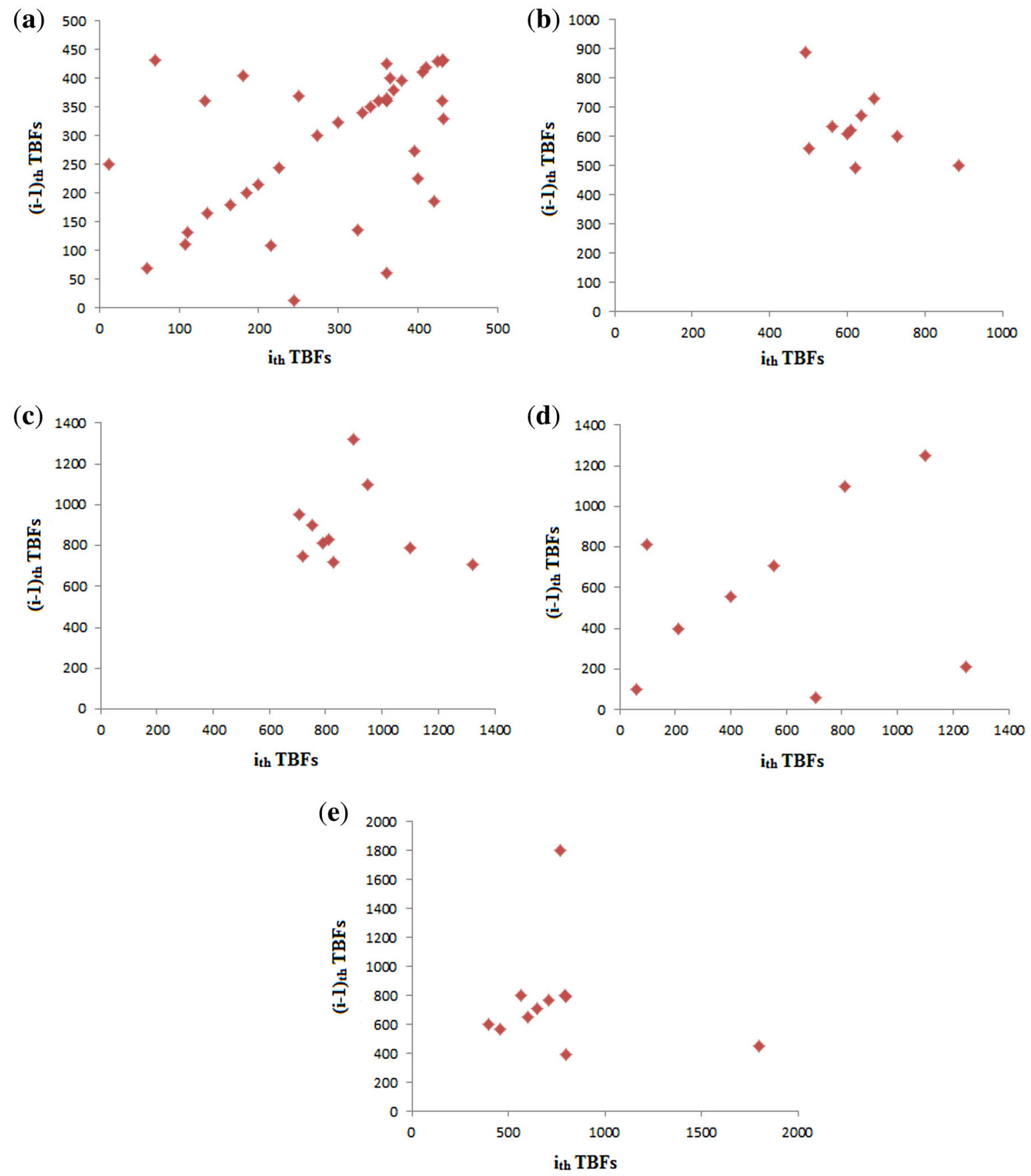

Figure 5. Plots confirming independence of data for (a) Jaw crusher unit, (b) Liner plate, (c) Tie rod, (d) Jaw plate and (e) Back toggle.

and incomplete data can be analyzed by this method [6-8].

In this study, TTT-plot is used to analyze rate of failures of crusher and its components considering time between successive failures (TBFs). Since this is often not the case for components of mechanical equipment like crushers, a graphical plot is found to be more informative. TTT-plots are indicative of the components increase or decrease in failure rates. It is used to determine the failure rate and to schedule maintenance of ageing components $[9,10]$. To develop a TTT-plot, following steps were considered:

(a) Time between failures (TBF) is structured as $0 \leq \mathrm{t}_{0} \leq \mathrm{t}_{1} \leq \mathrm{t}_{2} \ldots \leq \mathrm{t}_{\mathrm{n}}$

b) $S_{i}$ is determined from $S_{i}=n t_{1}+(n-1)\left(t_{2}-t_{1}\right)+$ $\cdots+(n-i+1)\left(t_{(i)}-t_{(i-1)}\right)$

(c) $\mathrm{X}$ co-ordinate, $(\mathrm{i} / \mathrm{n})$

(d) Y co-ordinate, $\mathrm{U}_{\mathrm{i}}=\mathrm{S}_{(\mathrm{i})} / \mathrm{S}_{(\mathrm{n})}$ 
Table 2. Result of Analysis with LDA Test.

\begin{tabular}{lccccccc}
\hline & \multicolumn{5}{c}{ LDA statistic } \\
\cline { 2 - 6 } System/subsystem & Exponential & \multicolumn{1}{c}{ Normal } & Lognormal & Gamma & Weibull & Logistic & Best fit model \\
\hline Jaw crusher & 43.98 & 1.08 & 1.28 & 3.83 & 0.33 & 6.53 & Weibull \\
Liner plate & $8.52 \times 10^{-8}$ & 0.010 & $1.73 \times 10^{-5}$ & $1.34 \times 10^{-9}$ & $1.0 \times 10^{-10}$ & 0.012 & Weibull \\
Tie rod & $5.36 \times 10^{-8}$ & $2.34 \times 10^{-7}$ & $7.0 \times 10^{-7}$ & $1.0 \times 10^{-10}$ & $1.0 \times 10^{-10}$ & $5.79 \times 10^{-6}$ & Weibull \\
Jaw plate & $1.0 \times 10^{-10}$ & $3.03 \times 10^{-7}$ & $5.5 \times 10^{-9}$ & $4.42 \times 10^{-8}$ & $1.0 \times 10^{-10}$ & $2.45 \times 10^{-7}$ & Weibull \\
Back toggle & $1.2 \times 10^{-10}$ & $3.91 \times 10^{-8}$ & $1.2 \times 10^{-10}$ & $2.24 \times 10^{-7}$ & $1.0 \times 10^{-10}$ & $1.15 \times 10^{-8}$ & Weibull \\
\hline
\end{tabular}

Table 3. Maximum likelihood estimation of the Weibull parameter.

\begin{tabular}{lcc}
\hline System/subsystem & $\beta$ & $\eta$ \\
\hline Jaw crusher & 1.17 & 290 \\
Liner plate & 4.33 & 631 \\
Tie rod & 3.18 & 888 \\
Jaw plate & 0.62 & 788 \\
Back toggle & 1.28 & 757 \\
\hline
\end{tabular}

Where,

$\mathrm{i}=\mathrm{i}_{\mathrm{th}}$ number of successive failure $(\mathrm{i}=1,2,3 \ldots \mathrm{n})$

$\mathrm{n}=$ number of successive failures and total 40 successive failures have been considered in this study

$\mathrm{S}_{\mathrm{i}}=$ total time on test at $\mathrm{i}_{\text {th }}$ successive failure

$\mathrm{S}_{\mathrm{n}}=$ total time on test at all successive failures under study and is equal to 11738 in this case

The values $i / n$ and $U_{i}$ will lie between 0 and 1 . The graphic representation of TTT is formed by plotting $i / n$ on the horizontal axis and Ui on the vertical axis. In general, the plot of the scaled time-on-test transform is within a unit square. The plotted points are connected by straight lines. For an exponential distribution, the TTT-plot is close to the diagonal of a square unit. The departure of the plot from the diagonal indicates the behavior of the failure rate. The TTT-plot runs along and nearly coincides with the diagonal of the square in case of constant failure rate. When the TTT plot concaves downward, it suggests increase in failure rate, that is, the condition of unit or the machine as a whole is deteriorating in terms of failure. If the plot concaves upward, it would suggest that failure rate is decreasing, that is, the condition of individual unit or the total machine is improving and figure 3 explains such situations [11-13]. TTT-plot helps in obtaining the shape of the failure rate function which indicates failure rate and aging of components and decides most favorable time for preventive maintenance.

\subsection{Trend analysis of failure data}

To explore the presence of trend in the time between Failures (TBFs) data of jaw crushers and its components, the cumulative time between successive failures are plotted against cumulative number of failures. To test the TBFs for independence, the failure data are tested for serial correlation. To test the data for serial correlation, the TBF are plotted $(i-1)_{\text {th }}$ against the $i_{\text {th }}$ TBF data of jaw crushers and its components.

For identical test of data, the analysis is carried out using cumulative number of failure data and cumulative time between successive failure data. Corresponding plots are shown in figure 4 in which the data show a trend which confirms that they are identical.

For independence test of data, scatter plots are drawn between dependent and independent variables. The independent variable is the measured or recorded data whilst the dependent variable is the outcome. In independence test, the measured or independent variables are plotted in vertical axis. In this study, the ( $\mathrm{i}-1)_{\mathrm{th}} \mathrm{TBF}$ is a measured variable whereas $i_{\text {th }}$ TBF. Corresponding plots are shown in figure 5 in which the data show no correlation and thus they are independent.

\subsection{Nature of distribution and parameter estimation}

Tests have shown absence of any distinct correlationship among the failure data, thus iid assumption for the data set is not violated. To examine the nature of distribution of TBF data, Exponential, Weibull and Lognormal distributions are examined. The parameters of these three distributions are estimated by ML method using WEIBULL++ software. Life Data Analysis (LDA) test is used as a measure of goodness-of-fit of different distributions [14]. The result of the analysis is shown in table 2 .

The TBF data of the crusher and its components revealed that 2 parameter Weibull distributions is the best-fit model for describing the data. The parameters of the Weibull distribution are estimated by ML estimation. The details are presented in table 3 . The shape and scale parameter values of Weibull distribution are determined using ML estimation method. Where $\beta$ is shape parameter which is also known as the Weibull slope, $\eta$ is scale parameter which indicates the mean time between failures (MTBF) and $t$ is time failed which indicates the mean time to failure (MTTF) of a 

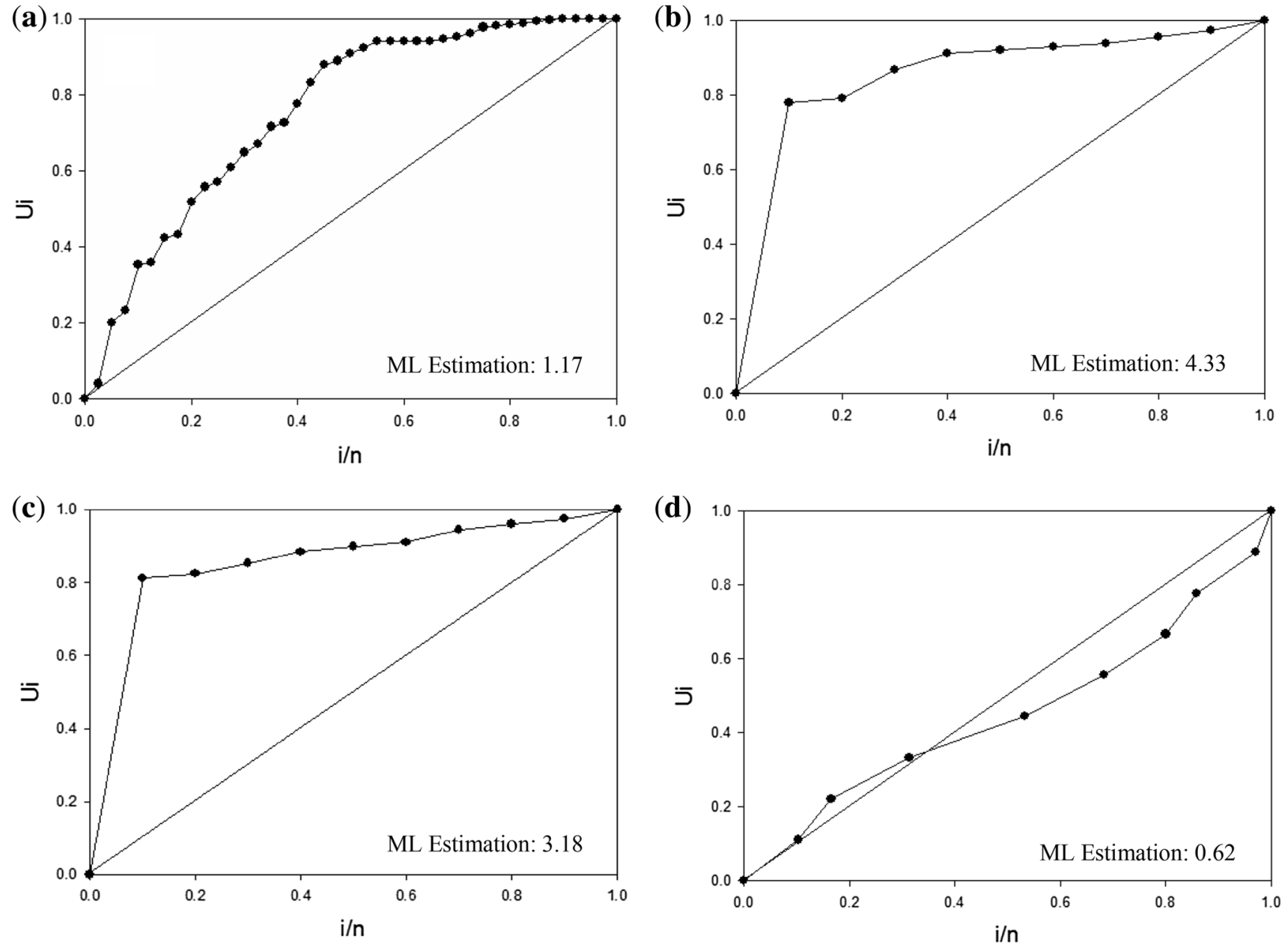

(e)

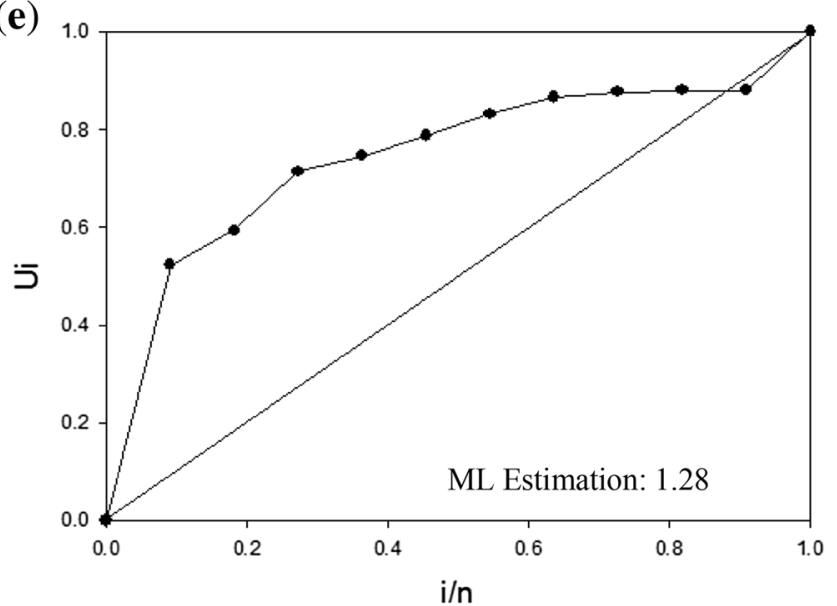

Figure 6. TTT-Plot of (a) Jaw crusher, (b) Liner plate, (c) Tie rod, (d) Jaw plate and (e) Back toggle.

component. The value of scale parameters $(\eta)$ are used to determine failure rates.

In ML estimation, the shape parameter value below 1 indicates decreasing nature of failure rates. When this value approaches 1, the failure rate becomes constant. Similarly, when value is above 1 , the failure rates show increasing trend. This complies with the TTT-plots of the crusher and its components in this study as presented in figure 6. For analysis through TTT-plotting, TBFs of crusher and its components are treated as complete samples. The TTT- 
Table 4. Data for TTT-plot of jaw crusher unit.

\begin{tabular}{|c|c|c|c|c|}
\hline $\begin{array}{l}\text { Serial } \\
\text { number of } \\
\text { successive } \\
\text { failure (n) }\end{array}$ & $\begin{array}{c}\text { Time before } \\
i_{\text {th }} \\
\text { successive } \\
\text { failure } \\
(\mathrm{TBF})\end{array}$ & $\mathrm{S}_{\mathrm{i}}=(\mathrm{TBF})_{\mathrm{i}} \times \sum(\mathrm{n})$ & $\begin{array}{c}\mathrm{U}_{\mathrm{i}}=\left(\mathrm{S}_{\mathrm{i}} /\right. \\
\left.\mathrm{S}_{\mathrm{n}}\right)\end{array}$ & $\mathrm{i} / \sum \mathrm{n}$ \\
\hline 1 & 12 & 480 & 0.041 & 0.025 \\
\hline 2 & 60 & 2354 & 0.201 & 0.05 \\
\hline 3 & 70 & 2734 & 0.233 & 0.075 \\
\hline 4 & 108 & 4140 & 0.353 & 0.1 \\
\hline 5 & 110 & 4212 & 0.359 & 0.125 \\
\hline 6 & 132 & 4982 & 0.424 & 0.15 \\
\hline 7 & 135 & 5084 & 0.433 & 0.175 \\
\hline 8 & 165 & 6074 & 0.517 & 0.2 \\
\hline 9 & 180 & 6554 & 0.558 & 0.225 \\
\hline 10 & 185 & 6709 & 0.572 & 0.25 \\
\hline 11 & 200 & 7159 & 0.61 & 0.275 \\
\hline 12 & 216 & 7623 & 0.649 & 0.3 \\
\hline 13 & 225 & 7875 & 0.671 & 0.325 \\
\hline 14 & 245 & 8415 & 0.717 & 0.35 \\
\hline 15 & 250 & 8545 & 0.728 & 0.375 \\
\hline 16 & 273 & 9120 & 0.777 & 0.4 \\
\hline 17 & 300 & 9768 & 0.832 & 0.425 \\
\hline 18 & 324 & 10320 & 0.879 & 0.45 \\
\hline 19 & 330 & 10452 & 0.89 & 0.475 \\
\hline 20 & 340 & 10662 & 0.908 & 0.5 \\
\hline 21 & 350 & 10862 & 0.925 & 0.525 \\
\hline 22 & 360 & 11052 & 0.942 & 0.55 \\
\hline 23 & 360 & 11052 & 0.942 & 0.575 \\
\hline 24 & 360 & 11052 & 0.942 & 0.6 \\
\hline 25 & 360 & 11052 & 0.942 & 0.625 \\
\hline 26 & 360 & 11052 & 0.942 & 0.65 \\
\hline 27 & 365 & 11122 & 0.948 & 0.675 \\
\hline 28 & 370 & 11187 & 0.953 & 0.7 \\
\hline 29 & 380 & 11307 & 0.963 & 0.725 \\
\hline 30 & 396 & 11483 & 0.978 & 0.75 \\
\hline 31 & 400 & 11523 & 0.982 & 0.775 \\
\hline 32 & 405 & 11568 & 0.986 & 0.8 \\
\hline 33 & 410 & 11608 & 0.989 & 0.825 \\
\hline 34 & 420 & 11678 & 0.995 & 0.85 \\
\hline 35 & 425 & 11708 & 0.997 & 0.875 \\
\hline 36 & 430 & 11733 & 1 & 0.9 \\
\hline 37 & 430 & 11733 & 1 & 0.925 \\
\hline 38 & 431 & 11736 & 1 & 0.95 \\
\hline 39 & 432 & 11738 & 1 & 0.975 \\
\hline 40 & 432 & 11738 & 1 & 1 \\
\hline
\end{tabular}

plots of back toggle, discharge chute liner plate, jaw plate, tie rod and crusher as a unit are presented in figure 6 .

\section{Result and discussion}

The trend and the serial correlation of the data have not contradicted the assumption of iid. The failure rate increases as age and wear take their toll on the crusher and
Table 5. Data for TTT-plot of liner plate.

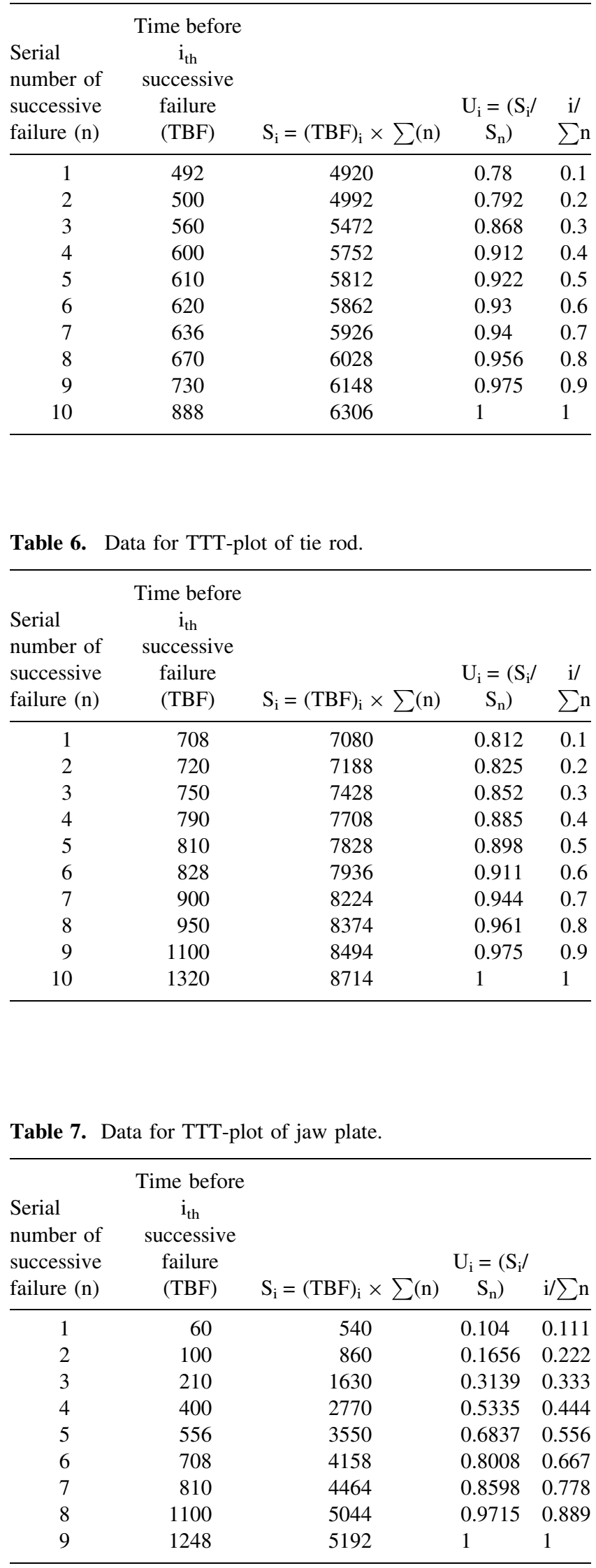


Table 8. Data for TTT-plot of back toggle.

\begin{tabular}{|c|c|c|c|c|}
\hline $\begin{array}{l}\text { Serial } \\
\text { number of } \\
\text { successive } \\
\text { failure (n) }\end{array}$ & $\begin{array}{c}\text { Time before } \\
i_{\text {th }} \\
\text { successive } \\
\text { failure } \\
(\mathrm{TBF})\end{array}$ & $\mathrm{S}_{\mathrm{i}}=(\mathrm{TBF})_{\mathrm{i}} \times \sum(\mathrm{n})$ & $\begin{array}{c}\mathrm{U}_{\mathrm{i}}=\left(\mathrm{S}_{\mathrm{i}} /\right. \\
\left.\mathrm{S}_{\mathrm{n}}\right)\end{array}$ & $\mathrm{i} / \sum \mathrm{n}$ \\
\hline 1 & 396 & 4356 & 0.523 & 0.091 \\
\hline 2 & 455 & 4946 & 0.593 & 0.182 \\
\hline 3 & 567 & 5954 & 0.714 & 0.273 \\
\hline 4 & 600 & 6218 & 0.746 & 0.364 \\
\hline 5 & 650 & 6568 & 0.788 & 0.455 \\
\hline 6 & 711 & 6934 & 0.832 & 0.545 \\
\hline 7 & 767 & 7214 & 0.865 & 0.636 \\
\hline 8 & 790 & 7306 & 0.876 & 0.727 \\
\hline 9 & 800 & 7336 & 0.88 & 0.818 \\
\hline 10 & 800 & 7336 & 0.88 & 0.909 \\
\hline 11 & 1800 & 8336 & 1 & 1 \\
\hline
\end{tabular}

the increasing failure rate also indicates that the entering wear-out phase of the equipment/components. This is illustrated in figures 4 and 5. The steps followed in TTTplot [15] are outlined in tables 4, 5, 6, 7 and 8. The TTTPlot for jaw crusher unit concaves downward which reveals increased rate of failures. This is also supported by the shape parameter value 1.17 of Weibull distributions. It also indicates that the jaw crusher as a whole unit is entering the wear-out phase.

The TBFs for liner plate, tie rod and back toggle show an increasing failure rate distribution as its TTT-plot indicates concave downward. This indicates preventive maintenance of the components is to be scheduled before a major failure. The increasing failure rate observation is in agreement with the ML estimation result shown in tables 5, 6 and 8 where the shape parameter for the liner plate, tie rod and back toggle are more than 1 , indicating increasing failure rate figures 6(b), (c) and (e). The normal life period is characterized by a low, relatively constant failure rate with failures that are considered to be random cases of stress exceeding strength phase of the equipment/components. It also specifies that the liner plate, tie rod and back toggle are entering the random failure rate phase.

TBFs of the jaw plate indicate decreasing failure rate distribution as its TTT-plot concaves upward figure 6(d). The decreasing failure rate observation is in agreement with the ML result in table 7 where the shape parameter for the jaw plate is less than 1. A decreasing failure rate describes a phenomenon where the probability of an occurrence in a fixed time interval in the future decreases over a time. A decreasing failure rate can describe a period of infant mortality where earlier failures are eliminated and correspond to the situation. Decreasing failure rate also indicates that the early failure of the equipment/components. It also specifies that the jaw plate is the periods of infant mortality where earlier failures are eliminated and correspond to the situation.

\section{Conclusion}

The study was aimed to estimate operational reliability of the crusher unit and its critical components using statistical tool like TBF, TTT-plot, LDA, iid, ML estimation, etc. The results of the analysis using a particular tool found in compliance with others.

\section{Nomenclature \\ $\beta \quad$ shape parameter \\ $\eta \quad$ scale parameter \\ $\mathrm{t}$ running time of equipment/components \\ i number of failure \\ n number of observations for time between failures \\ $\mathrm{U}_{\mathrm{i}}$ ratio of $\mathrm{Si} / \mathrm{Sn}$ \\ $\mathrm{S}_{\mathrm{i}} \quad$ is the TTT at time, $\mathrm{t}_{\mathrm{i}}$ \\ $\mathrm{S}_{\mathrm{n}} \quad$ is the TTT at $n$th failure}

\section{References}

[1] Kumar U, Klefsjo B and Granholm S 1989 Reliability investigation for a fleet of load haul dump machines in a Swedish mine. Reliab. Eng. Syst. Saf. 26: 341-361

[2] Kevin F, Ron B, Tige C and Nathan W 2002 A failure forecast method based on Weibull and statistical pattern analysis. Proc. Annu. Reliab. Maintainab. https://doi.org/10. 1109/rams.2002.981610

[3] Kara M, Mazhac, Kaebernickl H and Ahmedl A 2006 Determining the reuse potential of components based on life cycle data. Manuf. Technol. 54(1): 1-4

[4] Epsten and Sobel 1953 Life testing. J. Am. Stat. Assoc. 48: 486-502

[5] Barlow and Campo R 1975 Total time on test processes and applications to failure data analysis. In: Reliability and fault tree analysis SIAM; Philadelphia, pp. 451-481

[6] Chacko 2010 On total time on test transforms order. $R T \& A$ 04 (19) Vol.1

[7] Bengt K 1991 TTT-plotting-a tool for both theoretical and practical problems. J. Stat. Plan. Inference 99: 1-10

[8] Sun F B and Kececloglu D B 1999 A new method for obtaining the TTT plot for a censored sample. In: Reliability and Maintainability Symposium; Proceedings; pp. 112-117

[9] Barlow R E 1972 Statistical inference under order restrictions. Theory Appl. Isot. Regression; (No. 04; QA278. 7, B3)

[10] Zhao and Song Y H 2006 Risk assessment of strategies using Total Time on Test transform. IEEE; 1-4244-0493

[11] Gupta R C and Michalek J E 1985 Determination of reliability functions by the TTT transform. IEEE Trans. Reliab. 34(2): 175 
[12] Pham T P and Turkkan T G 1994 The Lorenz and the scaled total time on test transform curves: a unified approach. IEEE Trans. Reliab. 43(1): 76

[13] Akersten P A 1986 The bivariate TTT-plot-a tool for the study of non-constant failure intensities. In: Proceedings of Society of Reliability Engineers Symposium; SRE 86
[14] Chang S C and Li T F 2005 Estimation of component mean lifetimes of a masked system using unclassified system life data. Appl. Math. Comput. 169(2): 797-805

[15] Bergman B and Bengt K 1984 The total time on test concept and its use in reliability theory, operations research. Reliab. Maintainab. 32(3): 596-606 